Article

\title{
Design of Voltage Mode Electronically Tunable First Order All Pass Filter in \pm 0.7 V 16 nm CNFET Technology
}

\author{
Muhammad Masud ${ }^{1, *}$, Abu A'ain ${ }^{1,2}$, Iqbal Khan ${ }^{3}$ and Nasir Husin ${ }^{1}$ \\ 1 School of Electrical Engineering, Universiti Teknologi Malaysia, Johor Bahru 81310, Malaysia; \\ abukhari@uthm.edu.my (A.A.); nasirsh@fke.utm.my (N.H.) \\ 2 Institute for Integrated Engineering, Universiti Tun Hussein Onn, Johor 86400, Malaysia \\ 3 Department of Electrical Engineering, Umm Al Qura University, Makkah 21955, Saudi Arabia; \\ iqbalakhan19@rediffmail.com \\ * Correspondence: idreesmasud@yahoo.com; Tel.: +6-0166-128-954
}

Received: 11 November 2018; Accepted: 9 January 2019; Published: 15 January 2019

check for updates

\begin{abstract}
A novel voltage mode first order active only tuneable all pass filter (AOTAPF) circuit configuration is presented. The AOTAPF has been designed using $\pm 0.7 \mathrm{~V}, 16 \mathrm{~nm}$ carbon nanotube field effect transistor (CNFET) Technology. The circuit uses CNFET based varactor and unity gain inverting amplifier (UGIA). The presented AOTAPF is realized with three N-type CNFETs and without any external passive components. It is to be noted that the realized circuit uses only two CNFETs between its supply-rails and thus, suitable for low-voltage operation. The electronic tunability is achieved by varying the voltage controlled capacitance of the employed CNFET varactor. By altering the varactor tuning voltage, a wide tunable range of pole frequency between $34.2 \mathrm{GHz}$ to $56.9 \mathrm{GHz}$ is achieved. The proposed circuit does not need any matching constraint and is suitable for multi-GHz frequency applications. The presented AOTAPF performance is substantiated with HSPICE simulation program for $16 \mathrm{~nm}$ technology-node, using the well-known Stanford CNFET model. AOTAPF simulation results verify the theory for a wide frequency-range.
\end{abstract}

Keywords: APF; CNFET; pole-frequency; chirality; phase angle; tuning

\section{Introduction}

First order active all pass filter (APF) is an important analog signal processing (ASP) module. It is used for design of multiphase oscillators, phase-equalizers and high-quality-factor frequency-selective circuits. Several first order voltage mode (VM) single-ended (SE) APF circuit realizations have been reported in technical literature [1-8]. These APF circuits use a variety of efficient active-building-blocks (ABBs). However, these realized APFs are based on passive elements and large number of transistors count, which result in larger chip-area, lower slew rate, higher power dissipation and limitations to higher frequency operations. Few such APF configurations with low active and passive component counts are also available in the technical literature [9-18]. Some of these APF circuits also employ one or more ideal DC current-sources for biasing, which further increase the transistor count $[15,17,18]$.

From the integrated circuit point of view, the active only filters (AOFs) provide several attractive advantages like capability of operating at much higher frequencies, lesser chip area, low power dissipations and electronic tunabilty. As a result, few first order AOTAPFs are reported in the technical literature [19-21]. These AOTAPFs use the MOSFETs transconductance and intrinsic gate to source parasitic capacitance as filter design components; still, the frequency of operations falls with in $\mathrm{MHz}$ range. Moreover, these reported AOTAPF circuits also contain a large number of transistors. 
The APF circuits proposed in the technical literature [1-21] are based on bulk-semiconductortechnology. This technology faces serious challenges due to the persistent focus on transistor-scaling in nano meter regime for further continuation of Moore's law. These obstacles contain scattering-effect, decreased gate control, parasitic-capacitance, drain to source tunneling, channel mobility, thresholdvoltage-variability $[22,23]$. It has been proven experimentally that below $65 \mathrm{~nm}$-node, high-frequency analog circuit performance of silicon based semiconductor CMOS-technology is seriously degraded [24,25]. These emerging difficulties led the integrated-circuits industry to explore alternative materials and devices for below $65 \mathrm{~nm}$-node that work equally well for future high-frequency ASP applications and more than Moore's technologies devised by ITRS recently [26]. These include double gate FETs, FinFETs and carbon nanotube field effect transistors (CNFETs) etc. [22].

Among these new devices, CNFETs are self-evident frontrunners for future continuation of downscaling the feature length to further extend the saturated Moore's law in nanometer-regime in the case of CMOS-technology $[23,25,27]$. CNFET has potential to minimize the serious emerging problems of current CMOS-based technology due to its near ballistic-charge-conduction, smaller feature size, fast switching-speed, lower power-dissipation, higher cutoff frequency, lower parasitic capacitances and larger drive-current $[26,27]$. These outstanding features make the CNFET a potential candidate for future high-frequency analog circuit applications. Since CNFET introduction as an alternative to MOSFET, limited studies on CNFET-based analog filter design have been carried out [28-36].

In this paper, a new VM SE CNFET-only APF is proposed. The realized APF has a very compact circuit structure and it is free from external passive capacitors and resistors. The proposed AOTAPF employs only three N-type CNFETs instead of massive ABBs. Moreover, the proposed topology is tuneable over a wide frequency range. In addition, the proposed circuit is free from any matching constraint and it is a potential candidate for low power, low voltage and high-frequency applications. The AOTAPF circuit is substantiated with HSPICE-simulation using the Stanford-CNFET-model.

The rest of this paper is organized as follows. Section 2 describes a brief overview of CNFET. The unity gain inverting amplifier (UGIA) with its equivalent parasitic model is discussed in Section 3. Section 4, illustrates the proposed CNFET-based VM AOTAPF. The performance and simulation results of the proposed AOTAPF are given in Section 5. Comparison of the proposed circuit with other compact topologies of APFs in the technical literature is presented in Section 6. Finally, Section 7 concludes the work.

\section{Carbon Nano-Tube Field Effect Transistor}

Carbon nanotubes (CNTs) are graphite-cylindrical-sheets (GCSs), which are considered as the most promising material for future nano-electronic devices and applications, due to their exceptional electronic, mechanical, chemical and thermal properties. CNTs are classified as single-wall CNTs and multi-wall CNTs. Single-wall CNT is based on single GCS while multi-wall CNT consists of more than one GCS. The properties of single-wall CNT are dependent on the chirality-vector $\left(C_{h}\right)[28,29]$. The $C_{h}$ is defined by vector indices $n_{1}$ and $n_{2}$, which are positive-integers. The arrangement-angle of carbon atoms along the CNT is determined by $C_{h}$. The single-wall CNT can be of metallic or semiconducting behavior depending on the vector indices $n_{1}$ and $n_{2}$. If $\left|n_{1}-n_{2}\right|$ is an integer-multiple of three or $n_{1}=n_{2}$, the single-wall CNT behaves as metallic, otherwise it behaves as semiconductor. The $C_{h}$, diameter $\left(D_{T}\right)$ and threshold-voltage $\left(V_{t h}\right)$ of a CNT are related by the following equations.

$$
\begin{gathered}
C_{h}=a \sqrt{n_{1}^{2}+n_{2}^{2}+n_{1} n_{2}} \\
D_{T}=C_{h} / \pi \\
V_{t h}=a V_{\pi} / \sqrt{3} e D_{T}
\end{gathered}
$$


where, $e$ is the unit-electron-charge and $a$ is the graphene-lattice-constant with a value of $2.49 A^{\circ} . V_{\pi}$ is the $\pi$ to $\pi$ bond-energy in tight-bonding-model with a value of $3.033 \mathrm{eV} \mathrm{[30].} \mathrm{CNFET} \mathrm{is} \mathrm{one} \mathrm{of}$ the most attractive applications of CNT, which is obtained by replacing the MOSFET channel with one or more single-wall semiconducting CNTs as a channel material, as shown in Figure 1. Like conventional-MOSFET, CNFET is also a voltage-controlled-device and the current through the CNT based channel is controlled via gate voltage. CNFET gate is coupled capacitively with the beneath channel that consists of one or more narrow CNT. A single-CNT provides a limited amount of current. To enhance the channel current significantly, multiple parallel CNTs are incorporated in the channel. As compared to CMOS, where the design is dependent on the aspect ratio of transistors, a CNFET is usually optimized in terms of $D_{T}$, number of CNTs $\left(N_{T}\right)$ and inter-CNT pitch $\left(S_{T}\right)$. The $S_{T}$ is basically the distance between the centers of two adjacent CNTs under the same gate. The width of the CNFET gate $\left(W_{g}\right)$ is determined by the following equation [35]:

$$
W_{g}=\min \left(W_{\min },\left(N_{T}-1\right) S_{T}+D_{T}\right)
$$

where, $W_{\min }$ is the minimum gate width. The CNFET gate capacitance $\left(C_{g}\right)$, is one of the key device features and it significantly affects the performance, especially at high-frequencies. The $C_{g}$ is composed of three different capacitive components; coupling capacitance among the gate and adjacent contacts $\left(C_{g t g-t}\right)$, gate outer-fringe capacitance $\left(C_{f r-t}\right)$ and gate to channel capacitance $\left(C_{g c-t}\right)$. The $C_{g c-t}$ is further composed of two capacitances $C_{g c-m}$ and $C_{g c-e}$, which are capacitances of single-wall CNTs located in the middle and edge of CNFET respectively. The $C_{g c-t}$ components are shown in Figure 2. The CNFET gate capacitance parameters are:

$$
\begin{gathered}
C_{g t g-t}=W_{g} C_{g t g} \\
C_{f r-t}=L_{s} C_{f r} \\
C_{g c-t}=L_{g} C_{g c}
\end{gathered}
$$

where, $W_{g}$ and $L_{g}$ are the CNFET channel-width and channel-length respectively. $L_{s}$ is the length of doped source-side extension region. $C_{g t g}$ is the gate-coupling capacitance per unit gate-width, $C_{g c}$ is the gate to channel capacitance per unit channel-length and $C_{f r}$ is the gate outer-fringe capacitance per unit CNT length. Comparatively to $C_{g c}$ and $C_{g t g}$, the $C_{f r}$ capacitance magnitude is quite smaller and thus its effect can be ignored [35]. The $C_{g}$ thus can be approximated as:

$$
C_{g} \approx\left(C_{g t g} * W_{g}\right)+\left(C_{g c} * L_{g}\right)
$$

The drain/source capacitance $\left(C_{d / s}\right)$ can be determined by following relation.

$$
C_{d / s} \approx\left(C_{s u b} / C_{o x}+1\right)+\left(C_{g d / g s}\right)
$$

where, $C_{\text {sub }}$ is the capacitance between the CNFET channel and substrate, $C_{o x}$ is the capacitance between the CNFET gate and channel and $C_{g d / g s}$ is the capacitance of the CNFET gate to the drain/source contact. The ratio $C_{s u b} / C_{o x}$ is only important when CNFET substrate drive (switches) the gate. To assess the potential performance of CNFET, an accurate and efficient device-model is required, which incorporates typical non-idealities of CNFET device. Most available models of CNFETs in recent literature bear the drawback of ideal modeling, resulting in ignoring numerous important effects [36,37]. The Stanford CNFET model overcomes shortcomings of previous models by including several non-idealities like drain to source series resistance, interconnect wiring capacitance, finite scattering mean free path, inter CNT charge-screening-effect, effect of drain-source extension region 
and many more [38]. The Stanford CNFET model has been experimentally validated and it efficiently predicts the dynamic and transient performance with more than $90 \%$ accuracy [34].

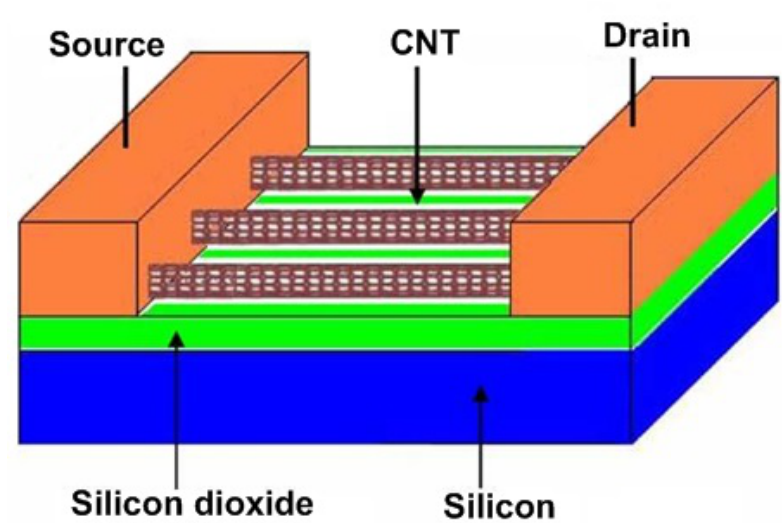

(a)

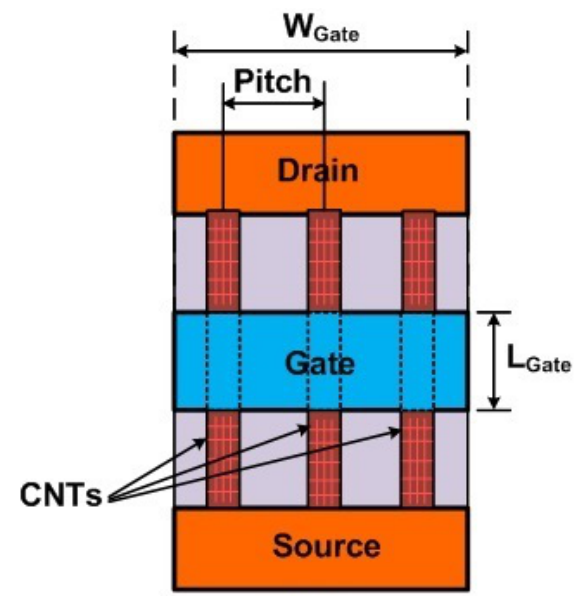

(b)

Figure 1. Carbon nanotube field effect transistor (CNFET) (a) Schematic; (b) Top-View.

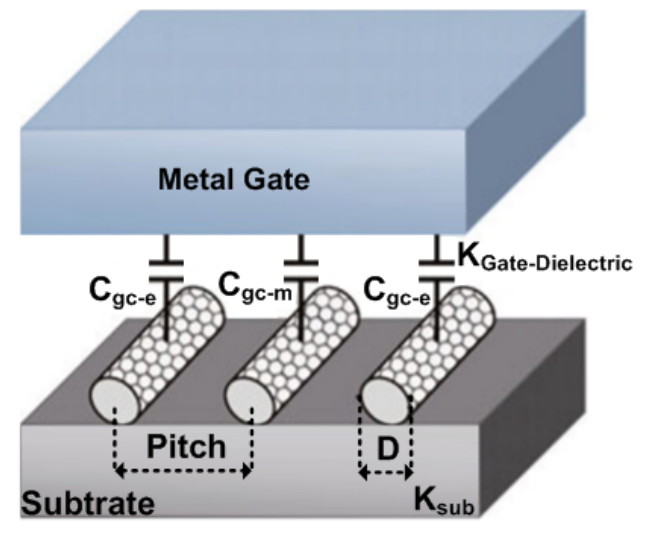

Figure 2. CNFET gate to channel capacitance.

Some important Stanford CNFET-model parameters are shown in Table 1.

Table 1. The Stanford CNFET model parameters.

\begin{tabular}{ccc}
\hline Parameter & Description & Value \\
\hline$V$ & Power-supply & $0.7 \mathrm{~V}$ \\
$L_{g}$ & Physical-channel-length & $16 \mathrm{~nm}$ \\
$S_{T}$ & CNTs-pitch & $10 \mathrm{~nm}$ \\
$\left(n_{1}, n_{2}\right)$ & CNTs-chirality & $(19,0)$ \\
Lceff & Mean free-path in intrinsic-CNT & $200 \mathrm{~nm}$ \\
$V_{f b n}$ & N-type CNFET flatband-voltage & 0 \\
High- $K_{o x}$ & Dielectric material of top-gate & $\mathrm{HfO}_{2}(16)$ \\
$L_{s}$ & Source-side length of doped-CNT & $16 \mathrm{~nm}$ \\
$L_{d}$ & Drain-side length of doped-CNT & $16 \mathrm{~nm}$ \\
$T_{o x}$ & Oxide-thickness & $4 \mathrm{~nm}$ \\
$K_{s u b}$ & Dielectric constant & $\mathrm{SiO}_{2}(4)$ \\
Leff $_{E_{f o}}$ & Fermi-level of n+ doped drain/source CNT-region & $15 \mathrm{~nm}$ \\
$N_{T}$ & Total number of CNT used per CNFET & $0.6 \mathrm{eV}$ \\
\hline
\end{tabular}

$\sim$ : Variable parameter. 


\section{CNFET Based UGIA}

The UGIA is one of the simplest types of ABB, which employs two N-type CNFETs as shown in Figure $3 a$ [16] and its symbol is shown in Figure 3b. Its transfer gain can be expressed as follows.

$$
\frac{V_{o}}{V_{i}}=-\frac{g_{m 2}}{g_{m 1}}
$$

where, $g_{m 1}$ and $g_{m 2}$ are the transconductance gains of the CNFETs $T_{1}$ and $T_{2}$ respectively. With symmetrical $T_{1}$ and $T_{2}$ on the same die, the $g_{m 1}=g_{m 2}$, the Equation (10) reduces to

$$
\frac{V_{o}}{V_{i}}=-1
$$

Thus, the circuit of Figure $3 a$, realizes an unity gain inverting amplifier (UGIA). The UGIA equivalent parasitic-model is shown in Figure 3c. Its input and output port resistances can be expressed as

$$
\begin{gathered}
r_{i}=r_{g} \\
r_{o}=r_{d s 1} \| r_{d s 2}
\end{gathered}
$$

where, $r_{g}$ represents the gate-resistance of transistor $T_{2}$ and $r_{d s 1}, r_{d s 2}$ are the channel-resistances of transistors $T_{1}$ and $T_{2}$ respectively. The UGIA input port has very high-resistance. The UGIA output port, being the voltage source, exhibits small resistance.

The impact of increasing CNTs $\left(N_{T}\right)$ of both the CNFETs of the UGIA on its performance is studied using HSPICE simulation tool. In the simulations, the Stanford CNFET model is used for the CNFETs with transistor parameters of Table 1. Figure 4 demonstrates the impact of $N_{T}$ on $r_{0}, C_{i}, C_{0}$, power dissipation and $-3 \mathrm{~dB}$ bandwidth of the UGIA. A single CNT carries approximately a constant current of $20 \mu \mathrm{A}$ [28]. The increase of $N_{T}$ of transistors increase the overall current drive capability and hence the transconductance [29]. The impact of increasing $N_{T}$ on UGIA $r_{o}$ is shown in Figure 4a. It is seen that by increasing $N_{T}$, the output resistance $r_{o}$ decreases. Since an increase in $N_{T}$ is equivalent to an increase in channel width of the CNFETs, $r_{o}$ decreases with the increase of $N_{T}$. The effects of increasing $N_{T}$ on input and output parasitic capacitances $C_{i}$ and $C_{o}$ of the UGIA, are shown in Figure $4 \mathrm{~b}$. It is observed that by increasing $N_{T}$, both the parasitic capacitances $C_{i}$ and $C_{o}$ increase. Figure $4 \mathrm{c}$ demonstrates the effect of increasing $N_{T}$ on the UGIA power dissipation. The power dissipation of UGIA increases as $N_{T}$ increases. The current drive capability of employed CNFETs increases with an increase of $N_{T}$, which leads to an increase in power dissipation. Figure $4 \mathrm{~d}$ demonstrates the effect of increasing $N_{T}$, on UGIA $-3 \mathrm{~dB}$ bandwidth. It is observed that by increasing $N_{T}$, the $-3 \mathrm{~dB}$ bandwidth of UGIA increases.

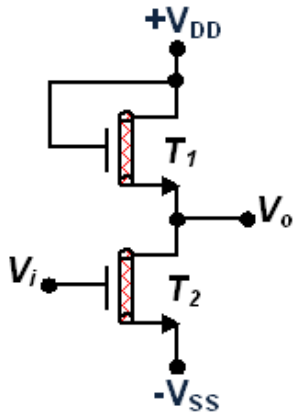

(a)

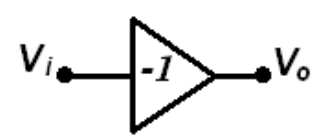

(b)

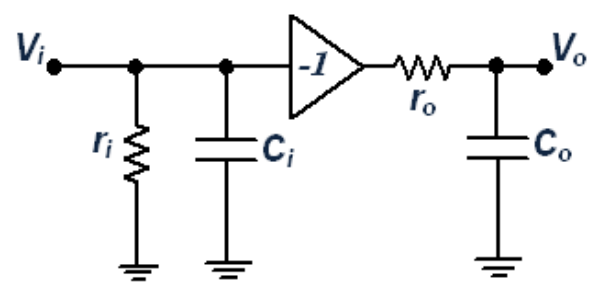

(c)

Figure 3. CNFET based UGIA: (a) Transistor-level realization; (b) Symbol; (c) Parasitic model. 


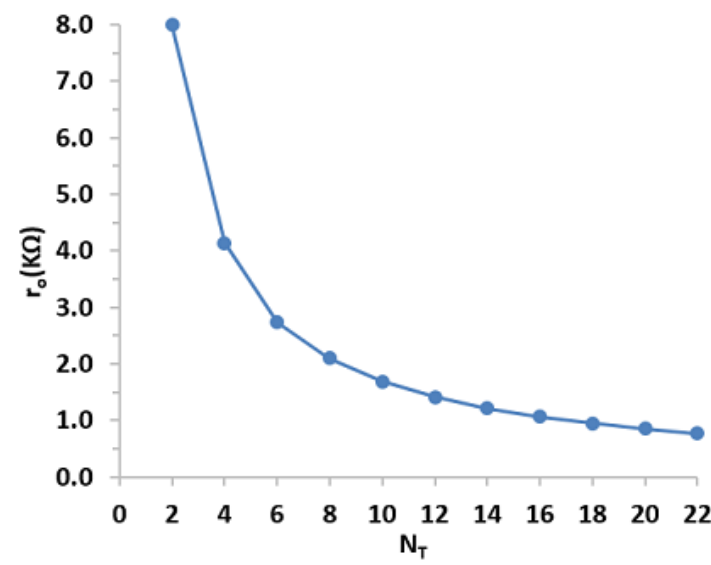

(a)

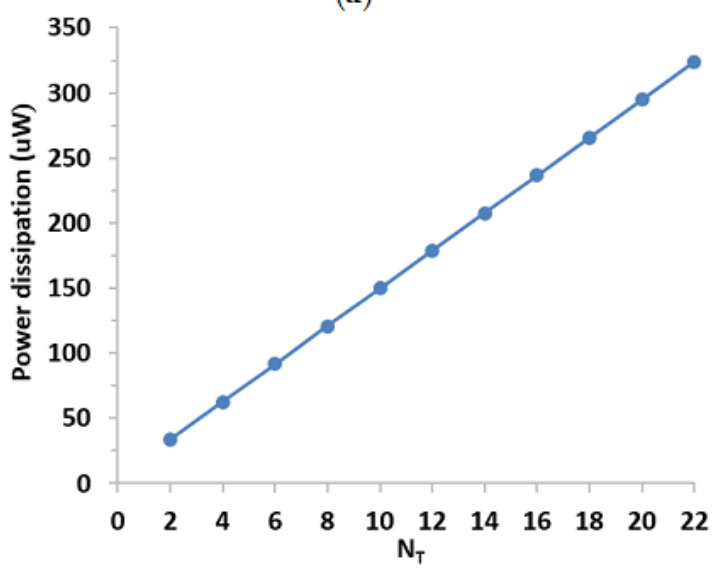

(c)

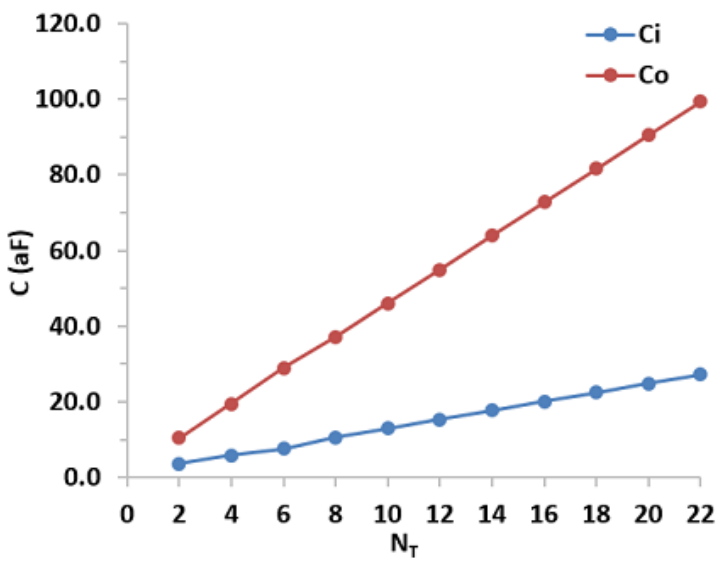

(b)

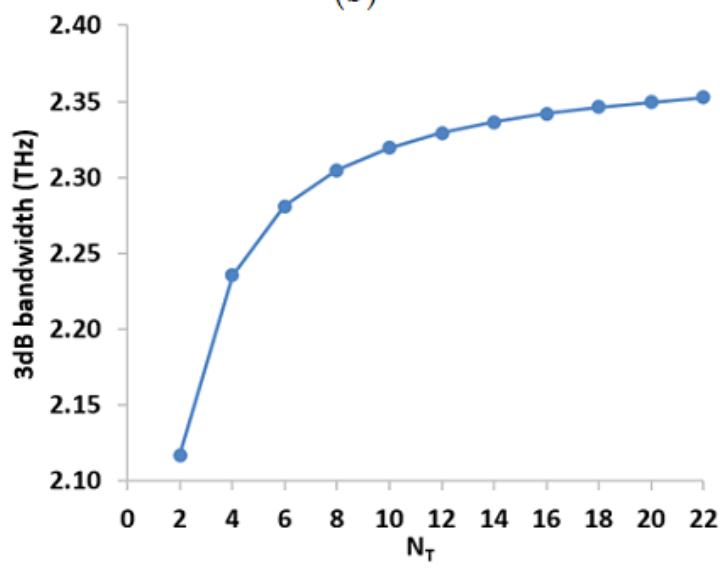

(d)

Figure 4. Effect of variation of $N_{T}$ on unity gain inverting amplifier (UGIA): (a) $r_{o} ;(\mathbf{b}) C_{i}$ and $C_{o}$; (c) Power dissipation; (d) $-3 \mathrm{~dB}$ bandwidth.

The transient and AC-analysis were performed with CNFET parameters of Table 1, with $N_{T}=2$. Figure 5 a shows the transient-response of UGIA input and output voltage at $50 \mathrm{GHz}$. Figure $5 \mathrm{~b}$ displays the UGIA AC simulation results of voltage-gain $\left(V_{o} / V_{i}\right)$. It is seen that the obtained voltage-gain magnitude is unity over a wide range of frequency. The $-3 \mathrm{~dB}$ frequency of employed UGIA voltage-gain is $2.1172 \mathrm{THz}$. This massive value of $-3 \mathrm{~dB}$ cutoff frequency makes the UGIA a potential candidate for the design of high frequency ASP modules.

The UGIA parasitic capacitance $C_{i}$ and resistance $r_{i}$ are found as $3.54 \mathrm{aF}$ and $1 \mathrm{~T} \Omega$ respectively. Figure $5 c$ displays the frequency response of UGIA output port resistance $\left(r_{o}\right)$, which is constant at $r_{o}=7.9921 \mathrm{k} \Omega$ over wide frequency-range. The $-3 \mathrm{~dB}$ cutoff frequency of the UGIA output-impedance is obtained as $1.9017 \mathrm{THz}$. The UGIA output parasitic-capacitance, $C_{o}$ is found as $10.472 \mathrm{aF}$, which is nearly insignificant for frequency-range up to several GHz. The total-harmonic-distortion (THD) of UGIA is determined by applying a $50 \mathrm{GHz}$ sinusoidal-signal to input with different voltage amplitudes. Simulation results are presented in Figure 6 a. It can be seen that THD is less than $1 \%$ for sinsoidal signal with amplitude of $200 \mathrm{mV}$. Monte Carlo simulation results of the UGIA were performed for 30-trials with transient and AC-sweep environment to see the influence of process-variations. Figure $6 \mathrm{~b}, \mathrm{c}$ illustrate the results of Monte Carlo analysis for UGIA transient and AC-sweep respectively. 


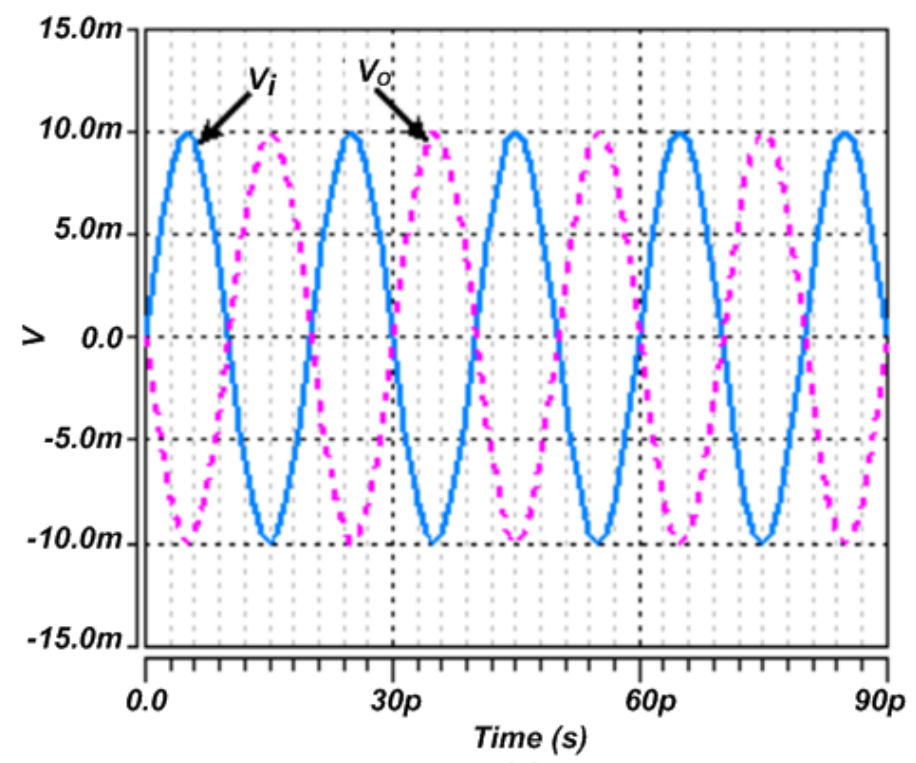

(a)

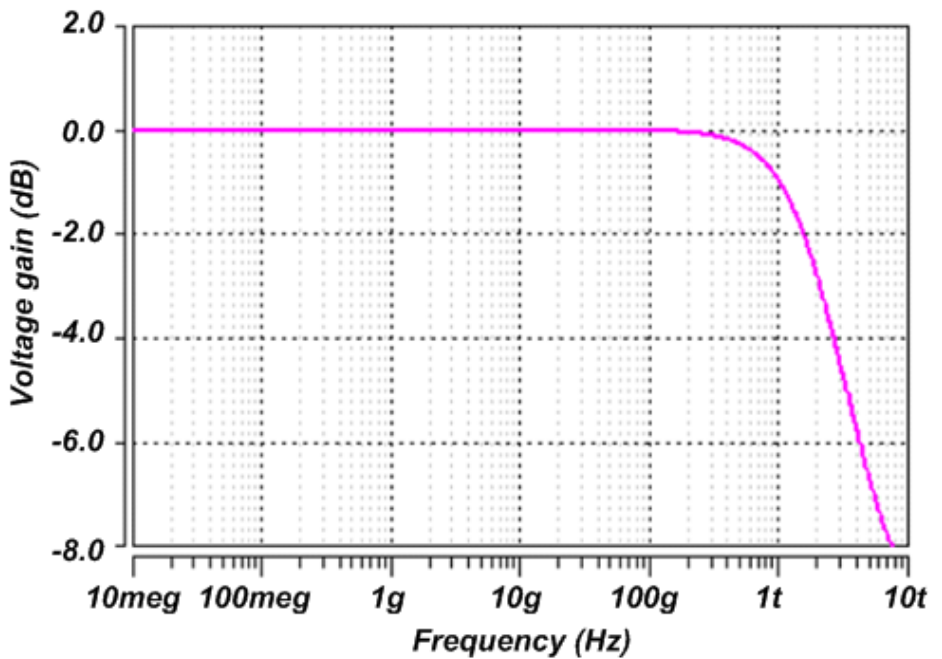

(b)

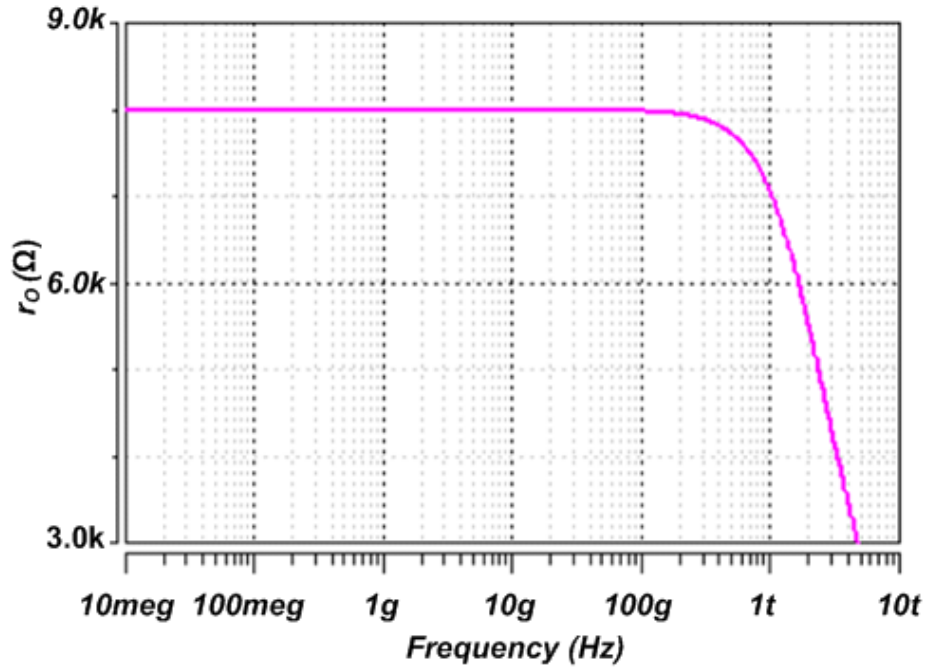

(c)

Figure 5. The UGIA: (a) Transient-response; (b) Frequency-response of Voltage-gain $\left(V_{o} / V_{i}\right)$; (c) Frequency-response of Output-impedance. 


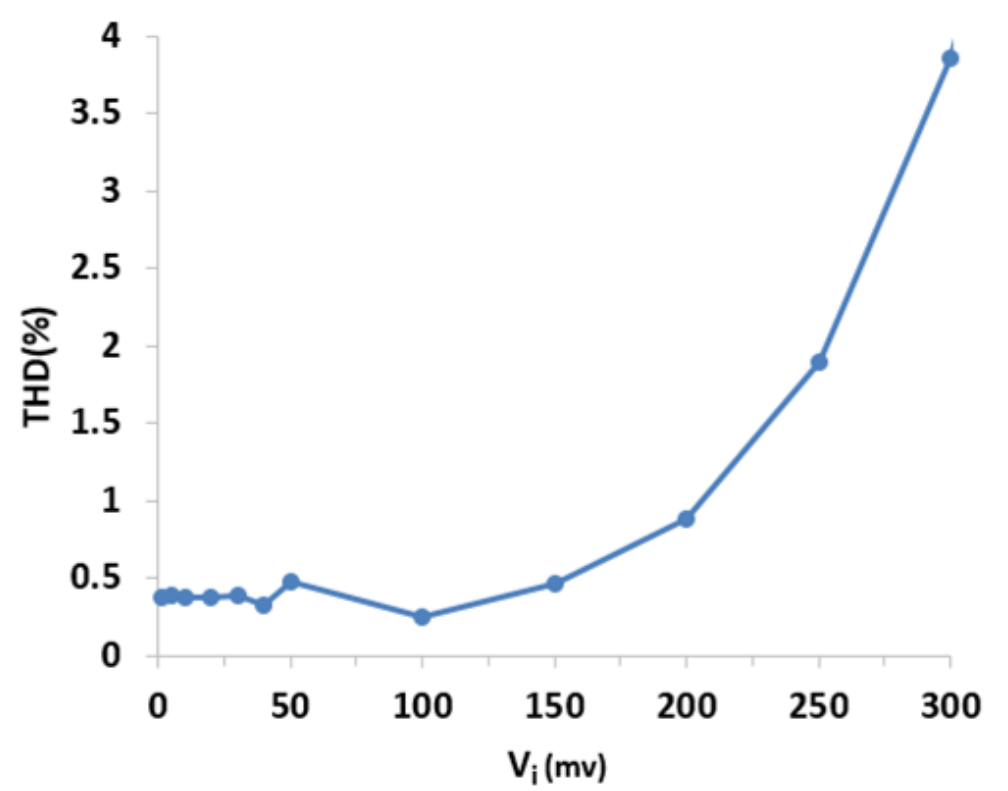

(a)

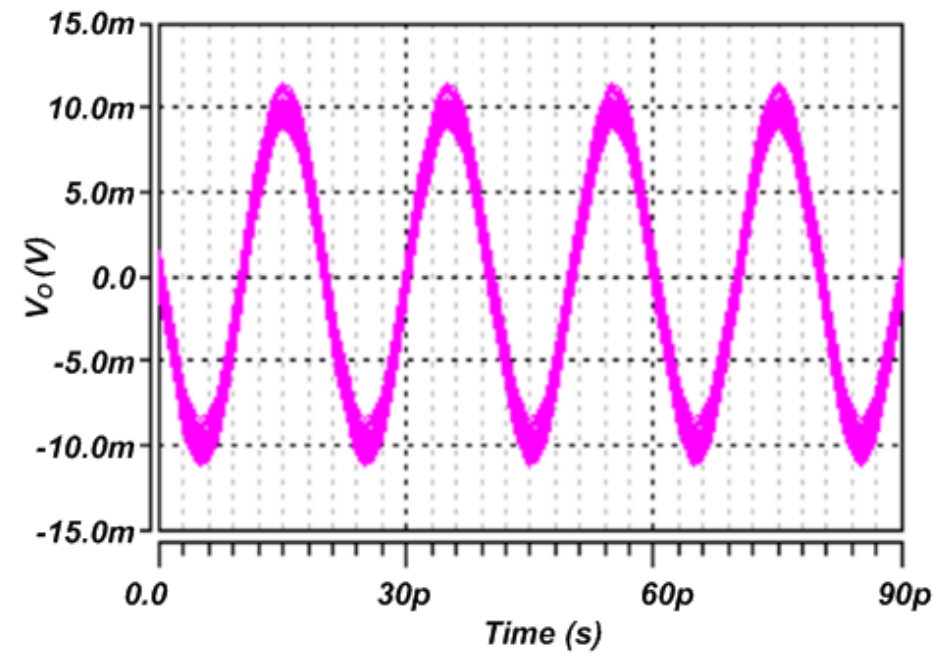

(b)

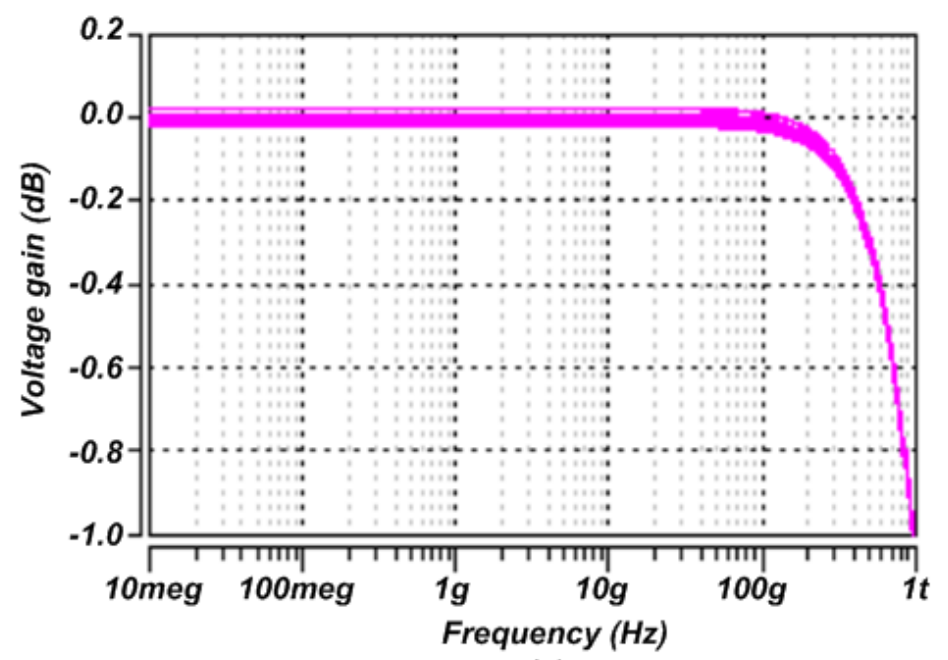

(c)

Figure 6. The UGIA: (a) THD Vs input voltage at $50 \mathrm{GHz}$; (b) Monte Carlo simulations for $V_{o}$ in time domain; (c) Monte Carlo simulations for voltage gain in frequency domain. 


\section{AOTAPF Circuit Description}

The basic scheme for first order APF section is given in Figure 7a. Its transfer function can be expressed as follows.

$$
\frac{V_{o}}{V_{i}}=\frac{s-a}{s+a}
$$

Its equivalent $\mathrm{RC}$ circuit along with a unity gain inverting amplifier is shown in Figure $7 \mathrm{~b}$, where pole frequency $\omega_{0}=a=1 / R C$. The CNFET version of Figure $7 \mathrm{~b}$ is given in Figure $7 \mathrm{c}$, where the unity gain inverting amplifier is replaced with UGIA of Figure $3 \mathrm{a}$ and the capacitor $\mathrm{C}$ is replaced with a CNFET based varactor capacitance $C_{v a r}$ between input and output. The N-Type CNFET based varactor used in Figure 7c is given in Figure 8a. Its equivalent symbol is shown in Figure 8b. The varactor CNFET source and drain are tied together and connected to the tuning control voltage $\left(V_{\text {tune }}\right)$ to form one capacitor terminal $(\mathrm{x})$, while the gate form the other terminal $(\mathrm{y})$. The varactor capacitance $\left(C_{\text {var }}\right)$ can be controlled by varying $V_{\text {tune }}$. The output resistance $r_{o}$ of UGIA is utilized to the benefit, to replace resistor $\mathrm{R}$ of Figure $7 \mathrm{~b}$. The circuit of Figure $7 \mathrm{c}$ results in an active only tunable all pass filter (AOTAPF).

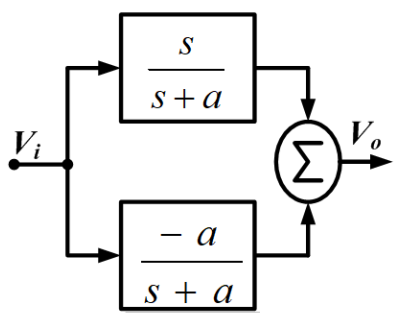

(a)

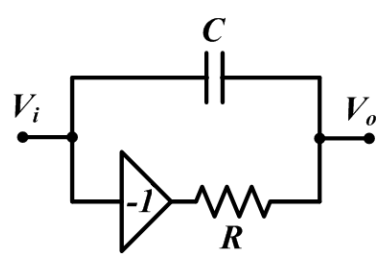

(b)

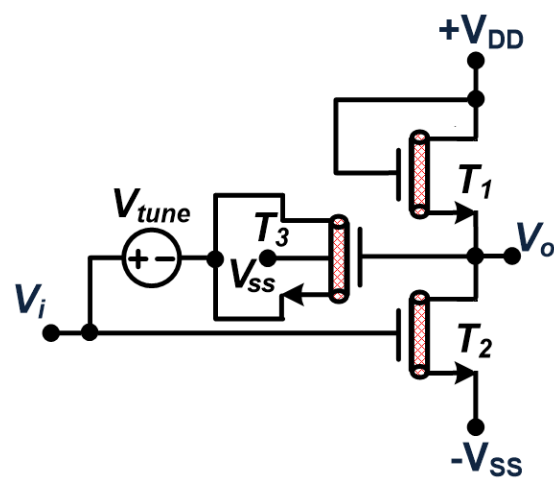

(c)

Figure 7. First order APF: (a) Basic scheme; (b) Equivalent circuit; (c) CNFET based implementation.

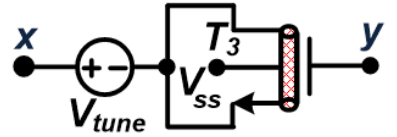

(a)

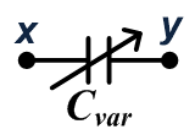

(b)

Figure 8. CNFET based varactor: (a) Transistor-level realization; (b) Symbol.

Ignoring the effect of extremely low valued output capacitance $C_{o}$ of UGIA, the proposed VM SE AOTAPF circuit shown in Figure 7c results in the following voltage transfer function (VTF).

$$
\frac{V_{o}}{V_{i}}=\frac{\left(s-\frac{1}{r_{o} C_{\text {var }}}\right)}{\left(s+\frac{1}{r_{o} C_{\text {var }}}\right)}
$$

From Equation (15), the pole-frequency $\left(\omega_{0}=\omega_{z}=\omega_{p}\right)$ and the phase-angle $(\phi)$, can be expressed respectively as:

$$
\begin{gathered}
\omega_{0}=\frac{1}{r_{0} C_{v a r}} \\
\phi=\pi-2 \tan ^{-1}\left(\omega r_{0} C_{v a r}\right)
\end{gathered}
$$


The Proposed AOTAPF pole-frequency incremental sensitivity with respect to the components $C_{v a r}$ and $r_{o}$ can be expressed as:

$$
S_{C_{v a r}}^{\omega_{o}}=S_{r_{o}}^{\omega_{o}}=-1
$$

From Equation (18), it is observed that the incremental sensitivities of the pole-frequency $\left(\omega_{0}\right)$ with respect to $C_{v a r}$ and $r_{o}$ are within unity in magnitude. By considering the UGIA non-ideal voltage-gain $(\alpha)$ and parasitic resistance $\left(r_{s}\right)$ of tuning control voltage $\left(V_{\text {tune }}\right)$ into consideration, the VTF of Equation (15) can be expressed as follows.

$$
\frac{V_{o}}{V_{i}}=\frac{\left(s\left(1-\frac{r_{s}}{r_{o}}\right)-\frac{\alpha}{r_{o} C_{v a r}}\right)}{\left(s\left(1+\frac{r_{s}}{r_{o}}\right)+\frac{1}{r_{o} C_{v a r}}\right)}
$$

From Equation (19) it is seen that the AOTAPF gain and pole-frequency $\left(\omega_{p}\right)$ is insensitive to $\alpha$. However, the zero-frequency $\left(\omega_{z}\right)$ is affected slightly due to $\alpha$. Moreover, the impact of source resistance $\left(r_{s}\right)$ on the performance of APF is negligible due to the presence of high valued output resistance $\left(r_{o}\right)$ of the UGIA $\left(r_{o} \gg r_{s}\right)$. Thus, the effect of $r_{s}$ can be ignored. By considering $\alpha$ into account, the non-ideal phase-angle for the realized filter can be expressed as follows.

$$
\phi=\pi-\tan ^{-1}\left(\frac{\omega r_{0} C_{v a r}}{\alpha}\right)-\tan ^{-1}\left(\omega r_{o} C_{v a r}\right)
$$

Thus, it is seen from Equation (20) that the phase-angle is slightly affected by $\alpha$. To examine the high-frequency performance of the realized AOTAPF, the UGIA parasitic impedances must be evaluated. By considering the $\alpha$ and non-ideal parasitic impedances of UGIA, the ideal VTF of the realized AOTAPF as illustrated by Equation (15) turns out to be

$$
\frac{V_{o}}{V_{i}}=\frac{C_{\text {var }}}{C_{\text {var }}+C_{o}} * \frac{\left(s-\frac{\alpha}{r_{o} C_{v a r}}\right)}{\left(s+\frac{1}{r_{o}\left(C_{v a r}+C_{o}\right)}\right)}
$$

From Equation (21), the $\omega_{z}$ and $\omega_{p}$ can be written as

$$
\begin{gathered}
\omega_{z}=\frac{\alpha}{r_{o} C_{v a r}} \\
\omega_{p}=\frac{1}{r_{o}\left(C_{v a r}+C_{o}\right)}
\end{gathered}
$$

It is evident from Equation (22) that the non-ideal factor $\alpha$ sightly affects the zero-frequency. In addition, it can be noticed from Equation (23) that UGIA parasitic capacitance $C_{o}$ affects the pole-frequency. The influence of the $C_{o}$ on the performance of the AOTAPF can be minimized by making $C_{v a r} \gg C_{0}$.

\section{Design and Verification}

To verify the proposed AOTAPF circuit, it is designed and simulated using HSPICE simulation tool with the Stanford CNFET model parameters of Table 1. Based on Equation (21), the value of the varactor capacitance $\left(C_{v a r}\right)$ is to be set sufficiently higher than the parasitic capacitance $\left(C_{o}\right)$, to evade the mismatch between zero and pole frequencies as well as non-unity gain for higher frequencies design. Figure 9 shows the capacitance tuning characteristics (C-V curves) of the realized CNFET varactor of Figure $8 \mathrm{a}$, with different values of $N_{T}$. It has been observed that by increasing $N_{T}$, the capacitance spread $\left(C_{\max }-C_{\min }\right)$, increases, which ultimately determines the frequency tuning range of AOTAPF. The $\mathrm{C}-\mathrm{V}$ relationship approximated by polynomial curve fitting is given in Appendix A. For instance, with $N_{T}=100$ and by setting $V_{\text {tune }}=-0.32 \mathrm{~V}$ for CNFET $T_{3}$, the observed $C_{\text {var }}$ is $0.40423 \mathrm{fF}$. Thus, with $r_{o}=7.9921 \mathrm{k} \Omega$, Equation (16) yields the pole frequency $f_{o}=49.26 \mathrm{GHz}$. 


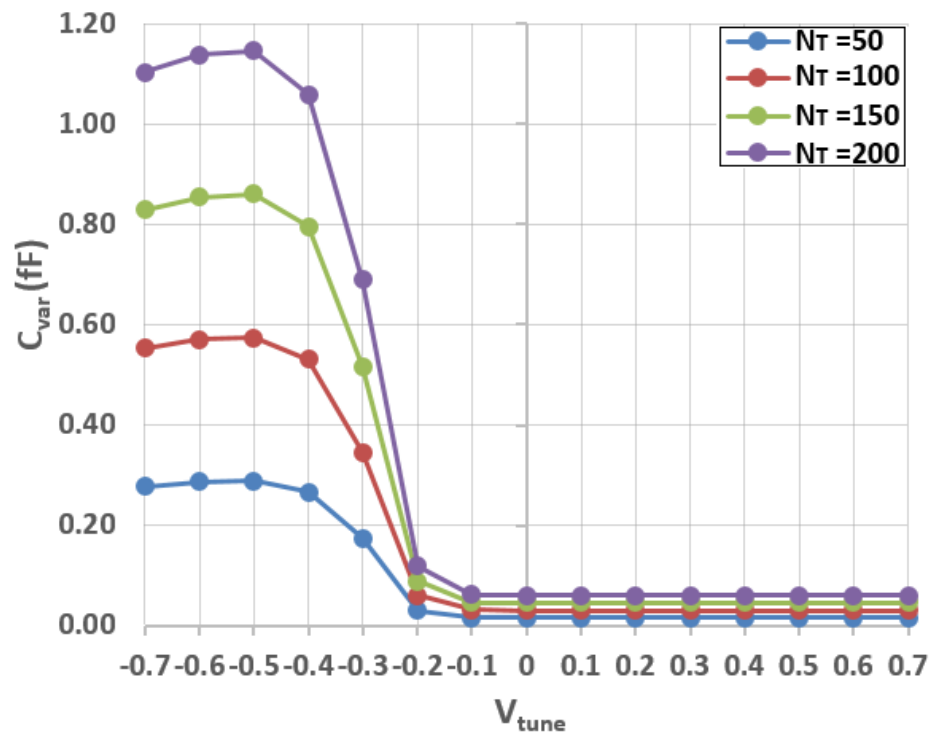

Figure 9. $\mathrm{CV}$ characteristics of varactor with different $N_{T}$.

The designed circuit was simulated with a sinusoidal input signal of $10 \mathrm{mV}$ peak. The results thus obtained are given in Figures 10-12. The transient response at the designed frequency of $f_{o}=$ 49.26 GHz is shown in Figure 10, where a phase shift of $90^{\circ}$ is evident. Figure 11a,b show the ideal and simulated magnitude and phase responses respectively. The proposed AOTAPF power dissipation is found to be $33.76 \mu \mathrm{W}$. It is noticed that the realized APF dissipates very small power, even at very high frequency of operation. Figure 12 shows the equivalent input and output noises against the frequency. It is noticed that the equivalent input noise and output noise for the realized AOTAPF at a designed pole-frequency of $49.26 \mathrm{GHz}$ are found as $6.822 \mathrm{nv} / \mathrm{Hz}$ and $6.761 \mathrm{nv} / \mathrm{Hz}$ respectively, which are satisfactorily low values. Monte Carlo simulation results of AOTAPF were performed for 30-trials with transient and AC-sweep environment to see the influence of process-variations. Figure 13a-c illustrate the results of the AOTAPF Monte Carlo analysis for transient, voltage gain and phase responses respectively. Here, it is observed from Figure 13 that there are no considerable variations of the filter performance characteristics.

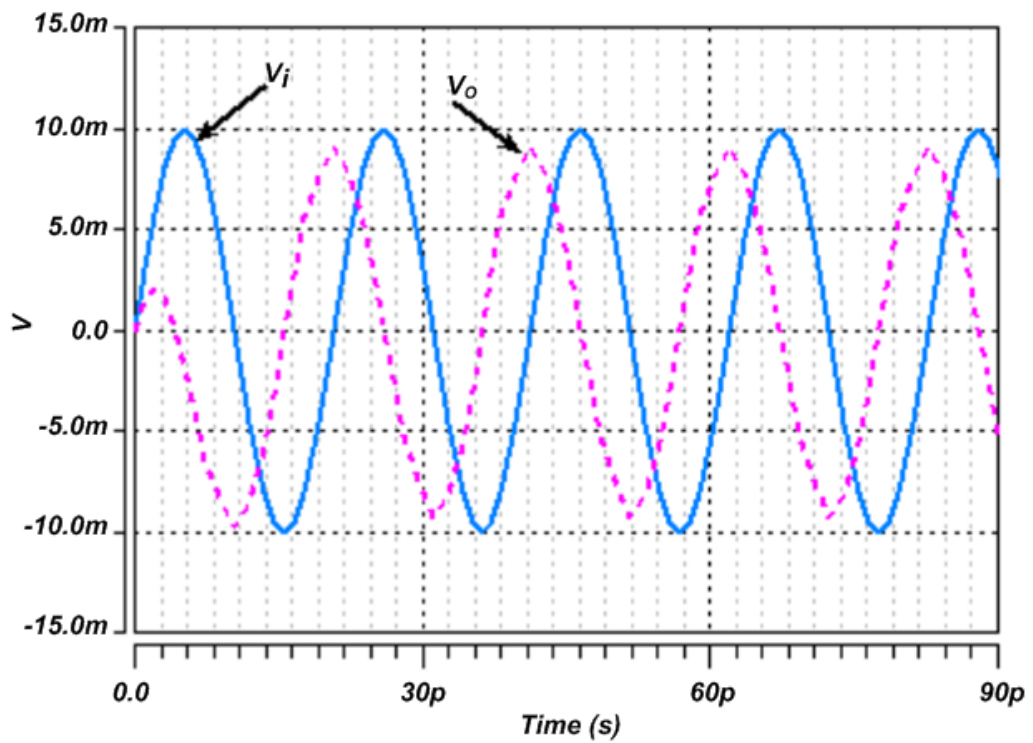

Figure 10. Transient-response of AOTAPF at pole- $f_{o}=49.26 \mathrm{GHz}$ and $V_{\text {tune }}=-0.32 \mathrm{~V}$. 


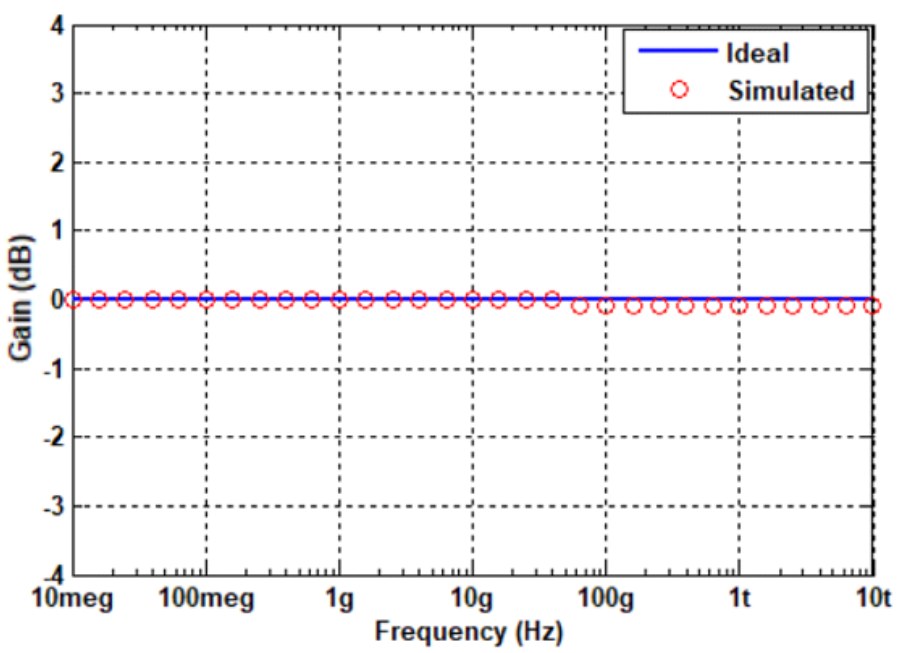

(a)

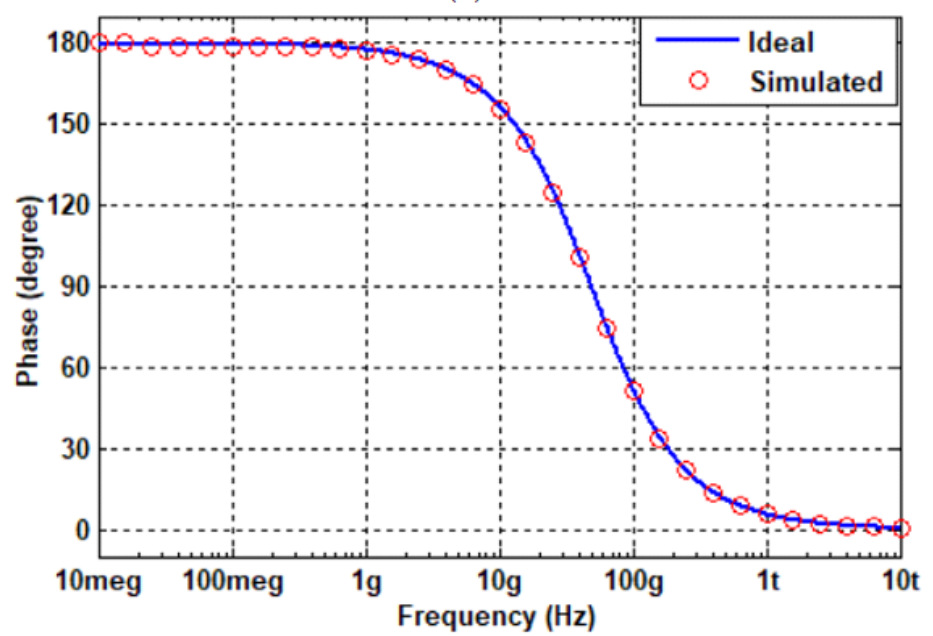

(b)

Figure 11. Ideal and simulated frequency-response of AOTAPF at $V_{\text {tune }}=-0.32 \mathrm{~V}$ : (a) Voltage gain; (b) Phase.

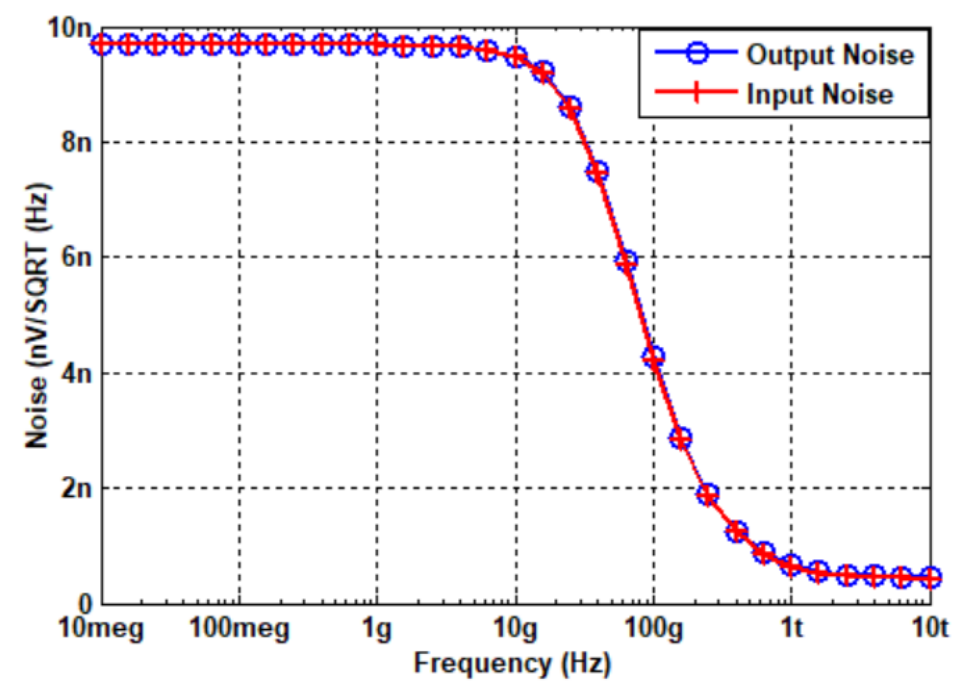

Figure 12. Frequency-response of input and output noise of AOTAPF at $V_{\text {tune }}=-0.32 \mathrm{~V}$. 


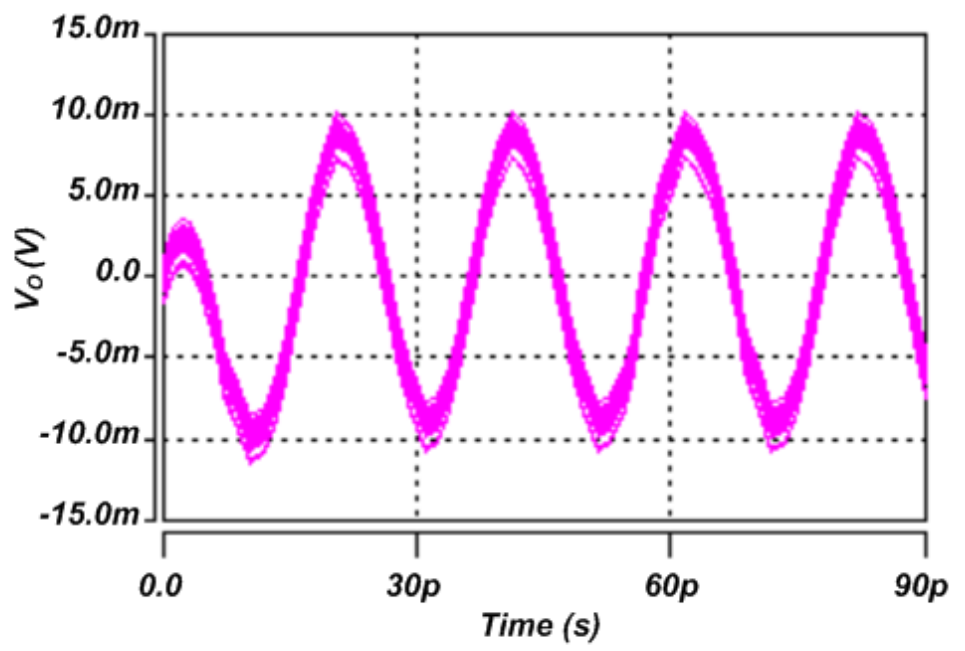

(a)

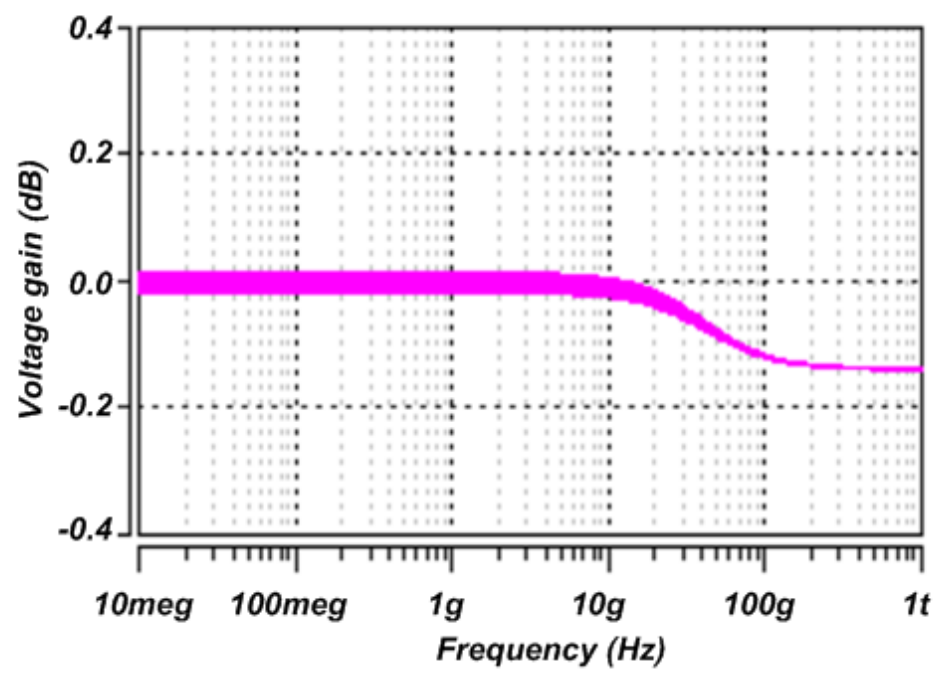

(b)

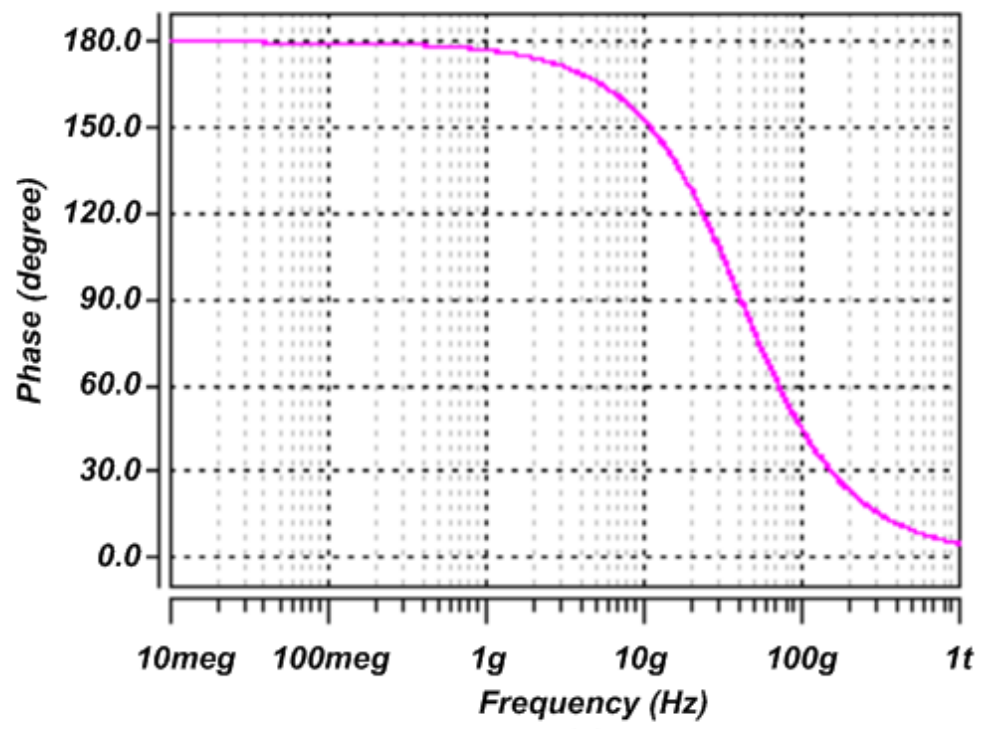

(c)

Figure 13. Monte Carlo simulations of AOTAPF for: (a) Time domain; (b) Voltage-gain $\left(V_{o} / V_{i}\right)$; (c) Phase. 
Next, to demonstrate the proposed circuit tunabilty feature, different tuning voltages $\left(V_{\text {tune }}\right)$ are applied to the varactor. By varying the $V_{\text {tune }}$ from $-0.5 \mathrm{~V}$ to $-0.3 \mathrm{~V}$ the varactor capacitance $\left(C_{v a r}\right)$ varies in the range of $0.574 \mathrm{fF}$ to $0.346 \mathrm{fF}$ respectively. Figure $14 \mathrm{a}$,b demonstrate the magnitude and phase responses respectively of the realized AOTAPF, at different values of $V_{\text {tune }}$. It is noticed from Figure $14 \mathrm{~b}$ that by varying the $V_{\text {tune }}$ from $-0.5 \mathrm{~V}$ to $-0.3 \mathrm{~V}$, the pole frequency of the proposed filter varies in the range of $34.2 \mathrm{GHz}$ to $56.9 \mathrm{GHz}$. This wide range of pole frequency by adjusting $V_{\text {tune }}$ makes the proposed circuit as a potential candidate for multi $\mathrm{GHz}$ applications. The transient responses of the proposed filter for different tune voltages are shown in Figure 15. A phase shift of $90^{\circ}$ is noticed for each pole frequency. The THD variations are found as $3.81 \%, 2.6 \%$ and $1.72 \%$ for $V_{\text {tune }}$ equal to $-0.30 \mathrm{~V},-0.33 \mathrm{~V}$ and $-0.50 \mathrm{~V}$ respectively. Thus, all the simulation results on the proposed AOTAPF support the theory.

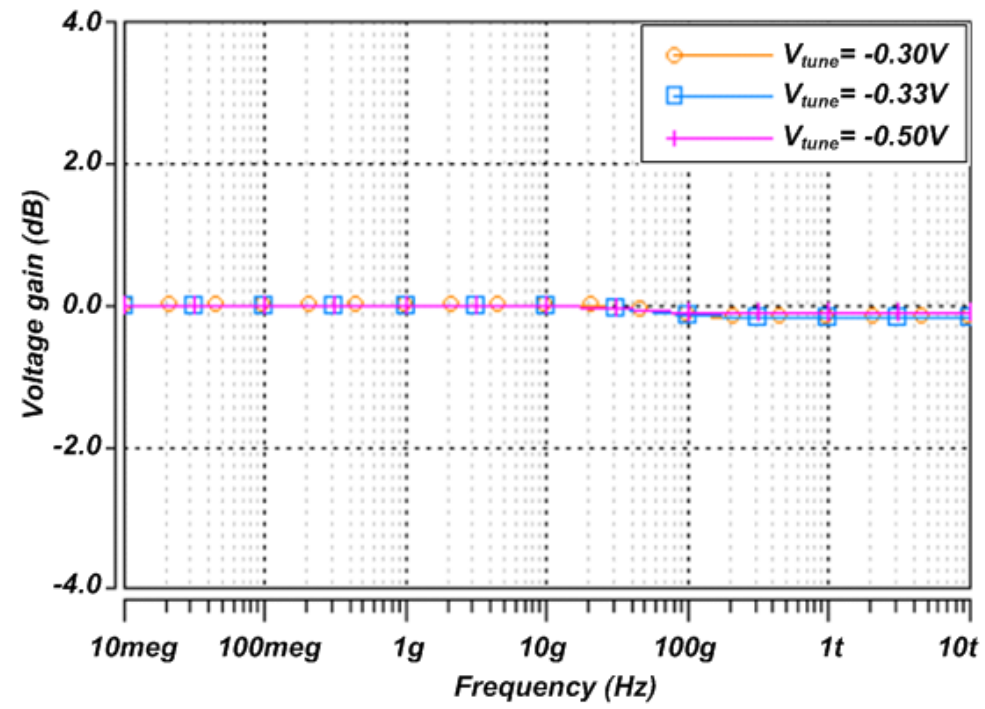

(a)

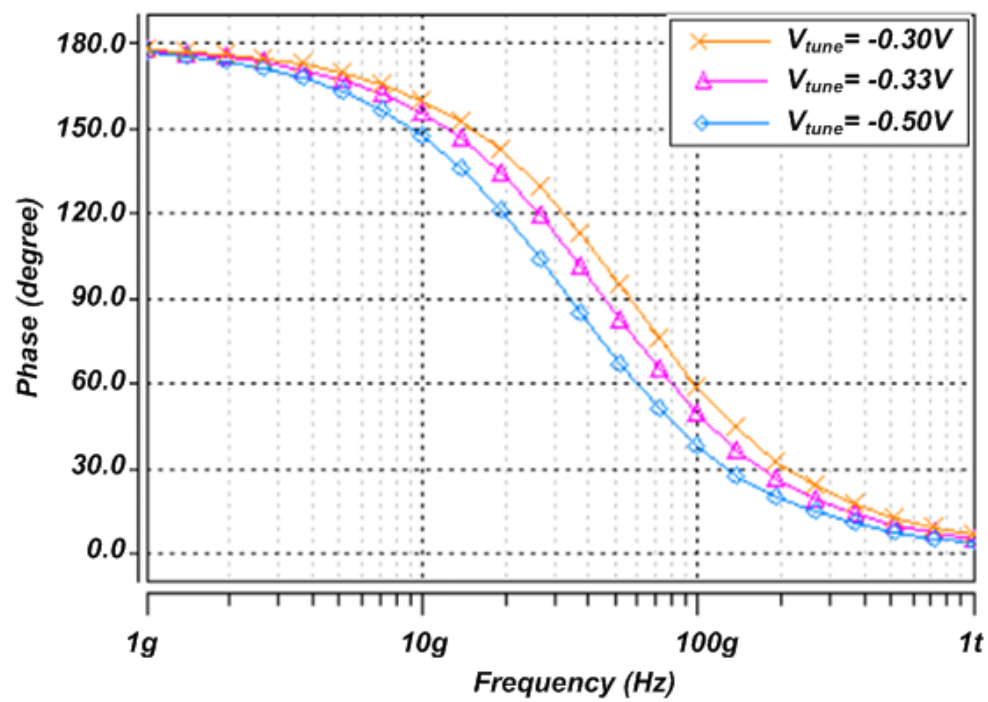

(b)

Figure 14. Frequency-response of AOTAPF at different values of $V_{\text {tune }}$ : (a) Voltage gain; (b) Phase. 


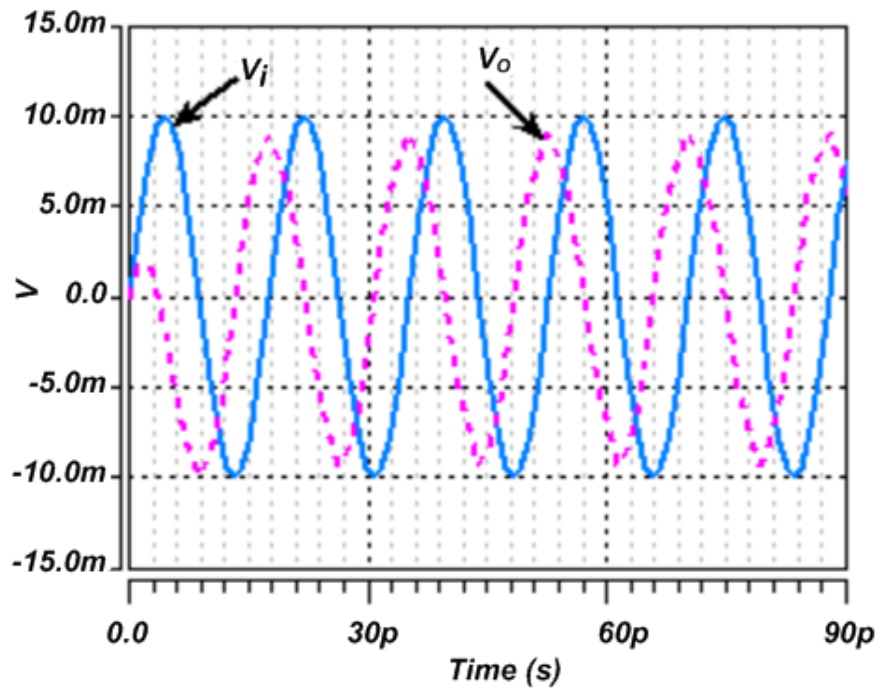

(a)

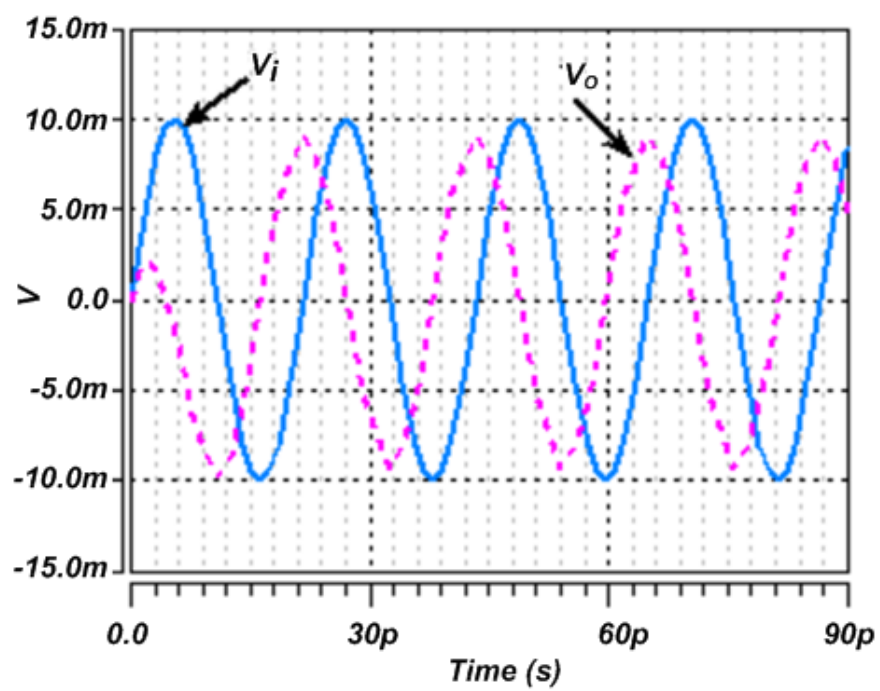

(b)

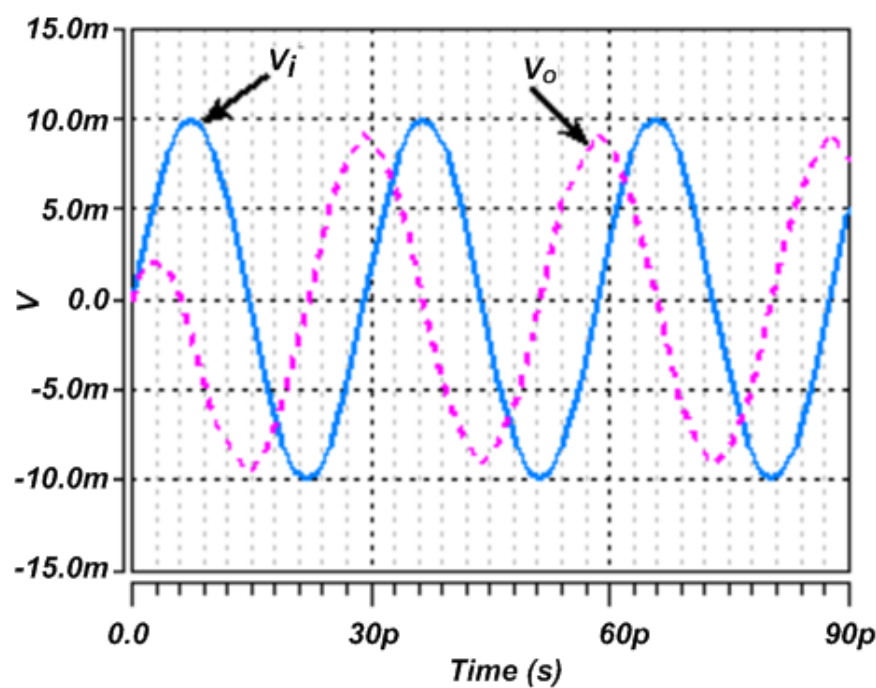

(c)

Figure 15. Transient-response of AOTAPF at different values of $V_{\text {tune }}$ : (a) $-0.30 \mathrm{~V}$; (b) $-0.33 \mathrm{~V}$; (c) $-0.50 \mathrm{~V}$. 


\section{Performance Comparison of the Proposed APF}

A brief comparison of the proposed AOTAPF with other available VM SE tunable APF circuit configurations is given in the Table 2. For comparison, only APFs realized with not more than 10 transistors are chosen. The APFs of [12-18] employ one or more external passive components, which result in occupying larger chip area and also suffer from slew rate limitations as well as wide tolerance. However, the proposed AOTAPF is free from any external passive component. The APFs presented in $[15,17-21]$ utilize one or more DC current sources for tunability of pole frequency via altering biasing current. However, additional transistors need to be employed for realization of these DC current supplies and thus the transistor count will further increase. It is to be noted like previously presented APFs of $[14,15]$, that the proposed AOTAPF is also suitable for low voltage operation as it employs only two active devices between its supply rails. The proposed AOTAPF circuit configuration is based on only three transistors, while the realized AOTAPF circuits of [19-21] use several transistors as they utilize ideal current sources. Although, the previously presented APF circuits of $[14,18]$ are also based on three transistors like the proposed AOTAPF, but they use one or more external passive components. In addition, the reported APF of [18] uses an ideal DC current source which will ultimately increase the transistor count. Table 2 shows that the CMOS-based APF circuit configurations are limited to $\mathrm{MHz}$ range while the proposed circuit operates in several $\mathrm{GHz}$ ranges.

Table 2. Comparison of AOTAPF with other reported APFs.

\begin{tabular}{|c|c|c|c|c|c|c|c|}
\hline Ref & $\begin{array}{l}\text { Ideal Current } \\
\text { Source Used }\end{array}$ & $\begin{array}{l}\text { Number of } \\
\text { Transistors }\end{array}$ & $\begin{array}{c}\text { Number of } \\
\text { External R/C }\end{array}$ & Technology (nm) & $\begin{array}{l}\text { Supply } \\
\text { Voltage }\end{array}$ & $\begin{array}{c}\text { Tuning } \\
\text { Range (Hz) }\end{array}$ & $\begin{array}{c}\text { Power } \\
\text { Dissipation }(\mathrm{mW})\end{array}$ \\
\hline [12] & No & 4 & $2 / 1$ & 180 & \pm 0.9 & $544.8 \mathrm{~K}$ to $2.9 \mathrm{M}$ & 20.4 \\
\hline [13] & No & 9 & $2 / 1$ & 350 & \pm 1.5 & $10 \mathrm{~K}$ to $56 \mathrm{~K}$ & - \\
\hline [14] & No & 3 & $2 / 1$ & 90 & \pm 0.45 & $103 \mathrm{~K}$ to $18.3 \mathrm{M}$ & 0.418 \\
\hline [15] & Yes & 5 & $0 / 1$ & 350 & \pm 1.5 & - & - \\
\hline [16] & No & 5 & $0 / 1$ & 180 & \pm 0.9 & $3.48 \mathrm{M}$ to $26.1 \mathrm{M}$ & - \\
\hline [17] & Yes & 6 & $0 / 1$ & 180 & \pm 0.9 & $1.07 \mathrm{M}$ to $9.44 \mathrm{M}$ & 10.5 \\
\hline [18] & Yes & 3 & $0 / 1$ & 130 & \pm 0.75 & - & 20.6 \\
\hline [19] & Yes & 4 & $0 / 0$ & 350 & \pm 1.65 & $105 \mathrm{M}$ to $205 \mathrm{M}$ & - \\
\hline [20] & Yes & 8 & $0 / 0$ & 350 & - & - & - \\
\hline [21] & Yes & 4 & $0 / 0$ & 350 & \pm 1.5 & - & - \\
\hline Proposed & No & 3 & $0 / 0$ & 16 & \pm 0.7 & $34.2 \mathrm{G}$ to $56.9 \mathrm{G}$ & 0.0337 \\
\hline
\end{tabular}

\section{Conclusions}

In this paper, a new single ended voltage mode first order all pass filter using CNFET based unity gain inverting amplifier and a varactor is presented. The proposed circuit is constructed with only three N-type CNFETs and thus it consumes very little area on chip. Since there are only two CNFETs stacked between the power-supply rails, it is able to work equally well at low voltages. The realized all pass filter circuit is free from external passive components and thus it is suitable for integrated circuit implementation. The proposed AOTAPF circuit non-ideal performance is also evaluated. The filter circuit is designed and verified with HSPICE, using the well-known Stanford CNFET model.

Initially, the CNFET-based unity gain inverting amplifier is studied for different numbers of CNTs. It was observed that with only two CNTs, the unity gain inverting amplifier yields optimal performance. Afterward, the CNFET-based varactor is simulated for different CNTs and variable DC voltages. This study enables the designer to choose the number of CNTs for the desired frequency range of operation. Then the realized AOTAPF circuit is studied in detail including gain, phase, and transient performance. The Monte Carlo analysis for process variations as well as THD simulation studies were also performed. The simulation results show a very good gain and phase characteristics at high frequencies with tunable pole-frequency range from $34.2 \mathrm{GHz}$ to $56.9 \mathrm{GHz}$. This makes the proposed topology a potential contestant for high frequency applications. It will be interesting to substantiate the all pass filter simulation results experimentally; however, due to the current non-availability of 
needed resources, experimental authentication is not performed. Physical realization of the presented AOTAPF may be a vital-direction for future extension of the proposed work.

Author Contributions: Conceptualization, M.M. and I.K.; methodology, M.M. and A.A.; software, M.M. and N.H.; validation, M.M., A.A. and I.K.; formal analysis, M.M. and N.H.; investigation, N.H.; data curation, M.M., A.A.; writing — original draft preparation, M.M., A.A., I.K. and N.H.; writing—review and editing, M.M. and I.K.; supervision, A.A., I.K. and N.H.

Funding: This research received no external funding.

Conflicts of Interest: The authors declare no conflict of interest.

\section{Abbreviations}

The following abbreviations are used in this manuscript:

$\begin{array}{ll}\text { APF } & \text { All pass filter } \\ \text { AOTAPF } & \text { Active only tuneable all pass filter } \\ \text { ASP } & \text { Analog signal processing } \\ \text { CNFET } & \text { Carbon Nanotube Field Effect Transistor } \\ \text { GCSs } & \text { Graphite-cylindrical-sheets } \\ \text { SE } & \text { Single-ended } \\ \text { THD } & \text { Total-harmonic-distortion } \\ \text { UGIA } & \text { Unity gain inverting amplifier } \\ \text { VTF } & \text { Voltage transfer function } \\ \omega_{0} & \text { Pole-frequency } \\ \omega_{z} & \text { Zero-frequency } \\ C_{v a r} & \text { varactor capacitance }\end{array}$

\section{Appendix A}

The capacitance tuning characteristics (C-V curves) of the realized CNFET varactor of Figure 8a, are obtained by sweeping the $V_{\text {tune }}$ from $-0.7 \mathrm{~V}$ to $+0.7 \mathrm{~V}$ for different $N_{T s}$ using HSPICE simualtion tool. The analytical relationship between the capacitance $C_{\text {var }}$ and the control voltage $V_{\text {tune }}$ can be obtained by polynomial curve fitting for fixed $N_{T}$. For $N_{T}=100$, the C-V relationship is approximated by following 2nd order polynomial expression:

$$
C_{\text {var }}=\left(-6.0601 V_{\text {tune }}^{2}-5.9693 V_{\text {tune }}-0.8934\right) f F
$$

\section{References}

1. Anju, U.; Kirat, P. First Order All Pass, Low Pass and High Pass Filters Using Differential Voltage Current Conveyors. J. Act. Passive Electron. Devices 2017, 12, 275-284.

2. Nandi, R.; Koushick, M.; Sandhya, P. Single-CFA first-order allpass filter. IEICE Electron. Express 2016, 13, 1-8. [CrossRef]

3. Maheshwari, S. Some analog filters of reduced complexity with shelving and multifunctional characteristics. J. Circuits Syst. Comput. 2018, 27, 1850150. [CrossRef]

4. Kumar, A.; Ajay, K.; Sajal, K. DXCCII-Based First Order Voltage-Mode All-Pass Filter. In Advances in Power Systems and Energy Management; Springer: Singapore, 2018; pp. 709-717.

5. Channumsin, O.; Worapong, T. Single VDBA-based phase shifter with low output impedance. In Proceedings of the 14th International Conference on Electrical Engineering/Electronics, Computer, Telecommunications and Information Technology (ECTI-CON), Phuket, Thailand, 27-30 June 2017; pp; 427-430.

6. Iqbal, S.; Psychalinos, C.; Parveen, N. First-order allpass filter using multi-input OTA. Int. J. Electron. 2013, 100, 1373-1382. [CrossRef]

7. Minaei, S.; Yuce, E. Novel voltage-mode all-pass filter based on using DVCCs. Circuits Syst. Signal Process. 2010, 29, 391-402. [CrossRef]

8. Herencsar, N.; Koton, J.; Hanak, P. Universal Voltage Conveyor and its Novel Dual-Output Fully-Cascadable VM APF Application. Appl. Sci. 2017, 3, 307. [CrossRef] 
9. Maundy, B.J.; Aronhime, P. A novel CMOS first-order all-pass filter. Int. J. Electron. 2002, 89, 739-743. [CrossRef]

10. Yuce, E. A novel CMOS-based voltage-mode first-order phase shifter employing a grounded capacitor. Circuits Syst. Signal Process. 2010, 29, 235-245. [CrossRef]

11. Herencsar, N.; Minaei, S.; Koton, J.; Vrba, K. In Voltage-mode all-pass filter design using simple CMOS transconductor: Non-ideal case study. In Proceedings of the 2015 38th International Conference on Telecommunications and Signal Processing (TSP), Prague, Czech Republic, 9-11 July 2015; pp. 677-681.

12. Yuce, E.; Minaei, S. A novel phase shifter using two NMOS transistors and passive elements. Analog Integr. Circuits Signal Process. 2010, 62, 77. [CrossRef]

13. Metin, B.; Cicekoglu, O. Tunable all-pass filter with a single inverting voltage buffer. In Proceedings of the 2008 Ph.D. Research in Microelectronics and Electronics, Istanbul, Turkey, 22 June-25 April 2008; pp. 261-263.

14. Metin, B.; Herencsar, N.; Cicekoglu, O. A low-voltage electronically tunable MOSFET-C voltage-mode first-order all-pass filter design. Radioengineering 2013, 22, 985-994.

15. Toker, A.; Özoğuz, S. Tunable allpass filter for low voltage operation. Electron. Lett. 2003, 39, $175-176$. [CrossRef]

16. Minaei, S.; Yuce, E. High input impedance NMOS-based phase shifter with minimum number of passive elements. Circuits Syst. Signal Process. 2012, 31, 51-60. [CrossRef]

17. Herencsar, N.; Minaei, S.; Koton, J.; Yuce, E.; Vrba, K. New resistorless and electronically tunable realization of dual-output VM all-pass filter using VDIBA. Analog Integr. Circuits Signal Process. 2013, 74, 141-154. [CrossRef]

18. Yucel, F; Yuce, E. A new electronically tunable first-order all-pass filter using only three NMOS transistors and a capacitor. Turk. J. Electr. Eng. Comput. Sci. 2016, 24, 3286-3292. [CrossRef]

19. Yildiz, H.A.; Ozoguz, S.; Toker, A.; Cicekoglu, O. On the realization of MOS-only allpass filters. Circuits Syst. Signal Process. 2013, 32, 1455-1465. [CrossRef]

20. Yıldız, H.A.; Toker, A.; Elwakil, A.S.; Ozoguz, S. MOS-only allpass filters with extended operating frequency range. Analog Integr. Circuits Signal Process. 2014, 81, 17-22. [CrossRef]

21. Metin, B.; Arslan, E.; Herencsar, N.; Cicekoglu, O. Voltage-mode MOS-only all-pass filter. In Proceedings of the 2011 34th International Conference on Telecommunications and Signal Processing (TSP), Budapest, Hungary, 18-20 August 2011; pp. 317-318.

22. Kuhn, K.J. Considerations for ultimate CMOS scaling. IEEE Trans. Electron Devices 2012, 59, $1813-1828$. [CrossRef]

23. Frank, D.J.; Dennard, R.H.; Nowak, E.; Solomon, P.M.; Taur, Y.; Wong, H.-S.P. Device scaling limits of Si MOSFETs and their application dependencies. Proc. IEEE 2001, 89, 259-288. [CrossRef]

24. Voinigescu, S.P.; Tomkins, A.; Dacquay, E.; Chevalier, P.; Hasch, J.; Chantre, A.; Sautreuil, B. A study of SiGe HBT signal sources in the 220-330-GHz range. IEEE J. Solid-State Circuits 2013, 48, 2011-2021. [CrossRef]

25. Schröter, M.; Claus, M.; Hermann, S.; Tittman-Otto, J.; Haferlach, M.; Mothes, S.; Schulz, S. In CNTFET-based RF electronics-State-of-the-art and future prospects. In Proceedings of the 2016 IEEE 16th Topical Meeting on Silicon Monolithic Integrated Circuits in RF Systems (SiRF), Austin, TX, USA, 24-27 January 2016; pp. 97-100.

26. Hayat, K.; Cheema, H.; Shamim, A. Potential of carbon nanotube field effect transistors for analogue circuits. J. Eng. 2013, 2013, 70-76. [CrossRef]

27. Prakash, P.; Sundaram, K.M.; Bennet, M.A. A review on carbon nanotube field effect transistors (CNTFETs) for ultra-low power applications. Renew. Sustain. Energy Rev. 2018, 89, 194-203. [CrossRef]

28. Nizamuddin, M.; Loan, S.A.; Alamoud, A.R.; Abbassi, S.A. Design, simulation and comparative analysis of CNT based cascode operational transconductance amplifiers. Nanotechnology 2015, 26, 395201. [CrossRef] [PubMed]

29. Loan, S.A.; Nizamuddin, M.; Alamoud, A.R.; Abbasi, S.A. Design and comparative analysis of high performance carbon nanotube-based operational transconductance amplifiers. NANO 2015, 10, 1550039. [CrossRef]

30. Masud, M.; A'ain, A.K.B.; Khan, I.A. In Reconfigurable CNTFET based fully differential first order multifunctional filter, Multimedia. In Proceedings of the 2017 International Conference on Signal Processing and Communication Technologies (IMPACT), Aligarh, India, 24-26 November 2017; pp. 55-59. 
31. Tripathi, S.; Ansari, M. S.; Joshi, A. M. In Low-Noise Tunable Band-Pass Filter for ISM 2.4 GHz Bluetooth Transceiver in \pm 0.7 V 32 nm CNFET Technology. In Proceedings of the International Conference on Data Engineering and Communication Technology, Maharashtra, India, 15-16 December 2017; pp. 435-443.

32. Sharma, J.; Ansari, M.S.; Sharma, J. In Current-Mode Electronically Tunable Resistor-less Universal Filter in \pm 0.5 V 32 Nm CNFET, Devices. In Proceedings of the 2014 International Conference on Circuits and Communications (ICDCCom), Ranchi, India, 12-13 September 2014; pp. 1-6.

33. Masud, M.; A'ain, A.K.B.; Khan, I.A. In CNFET Based Reconfigurable First Order Filter. In Proceedings of the 2017 9th IEEE-GCC Conference and Exhibition (GCCCE), Manama, Bahrain, 8-11 May 2017; pp. 1-9.

34. Sharma, J.; Ansari, M.S.; Sharma, J. In Electronically Tunable Resistor-less Universal Filter in $\pm 0.5 \mathrm{~V} 32 \mathrm{~nm}$ CNFET. In Proceedings of the 2014 Fifth International Symposium on Electronic System Design (ISED), Surathkal, Mangalore, India, 15-17 December 2014; pp. 206-207.

35. Moaiyeri, M.H.; Jahaniana, A.; Navia, K. Comparative performance evaluation of large FPGAs with CNFET and CMOS-based switches in nanoscale. Nano-Micro Lett. 2011, 3, 178-188. [CrossRef]

36. Guo, J.; Lundstrom, M.; Datta, S. Performance projections for ballistic carbon nanotube field-effect transistors. Appl. Phys. Lett. 2002, 80, 3192-3194. [CrossRef]

37. Natori, K.; Kimura, Y.; Shimizu, T. Characteristics of a carbon nanotube field-effect transistor analyzed as a ballistic nanowire field-effect transistor. J. Appl. Phys. 2005, 97, 034306. [CrossRef]

38. Deng, J.; Wong, H.-S.P. A compact SPICE model for carbon-nanotube field-effect transistors including nonidealities and its application-Part II: Full device model and circuit performance benchmarking. IEEE Trans. Electron Devices 2007, 54, 3195-3205. [CrossRef]

(C) 2019 by the authors. Licensee MDPI, Basel, Switzerland. This article is an open access article distributed under the terms and conditions of the Creative Commons Attribution (CC BY) license (http://creativecommons.org/licenses/by/4.0/). 